\title{
Amide-ligand hydrogen bonding in reverse micelles
}

Marc A. Walters ${ }^{1}$, Pamela M. Tadross ${ }^{1}$, Arnold L. Rheingold ${ }^{2}$, Lev N. Zakharov ${ }^{2}$, John Texter ${ }^{3}$, Danai Mudzudzu ${ }^{3}$

(1) Department of Chemistry, New York University, New York, NY 10003 (2) Department of Chemistry and Biochemistry, University of California-San Diego, San Diego, CA 92093 (3) College of Technology, Eastern Michigan University, Ypsilanti, MI

\section{Supporting Information}

\section{Synthetic Methods}

All reagents were used as received without further purification. Chloroacetamide and potassium ferricyanide were obtained from Aldrich and cetyldimethylamine was obtained from Fluka. Solvents were distilled and stored under nitrogen before use.

Preparation of CDA-Cl ${ }^{1,2}$

Chloroacetamide $(1.00 \mathrm{~g}, 10.7 \mathrm{mmol})$ and cetyldimethylamine $(3.6 \mathrm{~mL}, 10.7$

mmol) were combined acetonitrile and refluxed for 18 hours. A white crystalline product precipitated upon cooling the solution to room temperature. The product was filtered and washed with diethyl ether and dried under vacuum. Yield: 94\%. ${ }^{1} \mathrm{H}-\mathrm{NMR}\left(\mathrm{CDCl}_{3}\right)$ : 9.0, $6.6\left(\mathrm{~d}, \mathrm{NH}_{2}\right), 4.7(\mathrm{~s}, \mathrm{C \alpha}), 3.65(\mathrm{~m}, \mathrm{C} 1), 3.45\left(\mathrm{~s},{ }^{+} \mathrm{N}\left(\mathrm{CH}_{3}\right)_{2}\right), 1.71(\mathrm{~m}, \mathrm{C} 2), 1.30(\mathrm{~m}, \mathrm{C} 3-$ C15), $0.90 \mathrm{ppm}(\mathrm{t}, \mathrm{C} 16)$.

Preparation of $(\mathrm{CDA})_{3}\left[\mathrm{Fe}(\mathrm{CN})_{6}\right]^{3}$

Aqueous solutions of CDA-Cl $(1.00 \mathrm{~g}, 2.7 \mathrm{mmol})$ and potassium ferricyanide $(0.296 \mathrm{~g}, 0.9 \mathrm{mmol})$ were combined immediately produced yellow precipitate that was filtered, washed with water, and dried in air. Yield: 95\%. UV-Vis (Methanol): 262, 304, and $418 \mathrm{~nm} .{ }^{1} \mathrm{H}-\mathrm{NMR}\left(\mathrm{CDCl}_{3}\right)$ : 7.90, $6.00\left(\mathrm{~d}, \mathrm{NH}_{2}\right), 3.45(\mathrm{~s}, \mathrm{C \alpha}), 3.15(\mathrm{~m}, \mathrm{C} 1), 2.75(\mathrm{~s}$, $\left.{ }^{+} \mathrm{N}\left(\mathrm{CH}_{3}\right)_{2}\right), 1.70(\mathrm{~m}, \mathrm{C} 2), 1.20(\mathrm{~m}, \mathrm{C} 3-\mathrm{C} 15), 0.90 \mathrm{ppm}(\mathrm{t}, \mathrm{C} 16) .{ }^{1} \mathrm{H}-\mathrm{NMR}\left(\mathrm{DMSO}-\mathrm{d}_{6}\right)$ : $7.5\left(\mathrm{~d}, \mathrm{NH}_{2}\right), 3.60(\mathrm{~s}, \mathrm{C} \alpha), 3.40(\mathrm{~m}, \mathrm{C} 1), 3.10\left(\mathrm{~s},{ }^{+} \mathrm{N}\left(\mathrm{CH}_{3}\right)_{2}\right), 1.75(\mathrm{~m}, \mathrm{C} 2), 1.30$ (m, C3C15), 0.80 ppm (t, C16).

\section{Crystallization of $(\mathrm{CDA})_{3}\left[\mathrm{Fe}(\mathrm{CN})_{6}\right]$}

A saturated DMSO solution of the product was prepared and tightly covered. Over a period of 2 days, crystals formed in the solution. The crystals were isolated and dried under vacuum for 6 to 8 hours. Anal. Calcd. for $\mathrm{C}_{68} \mathrm{H}_{135} \mathrm{O}_{4} \mathrm{~N}_{12} \mathrm{SFe}$ : C, 64.16; $\mathrm{H}$, 10.7; N, 13.2. Found: C, 63.93; H, 11.05; N, 13.07.

\section{Experimental Methods}

\section{Dynamic Light Scattering Measurements}

Data was collected on a Protein Solutions DynaPro 99 instrument using $824.8 \mathrm{~nm}$ light at a scattering angle of $90^{\circ}$. All measurements were made at $20.0^{\circ} \mathrm{C}$. All samples were filtered through $0.22 \mu \mathrm{m}$ syringe filters prior to data collection. 


\section{${ }^{1} H$-NMR Measurements}

Proton NMR measurements were recorded on a Bruker AV-400 spectrometer at $300 \mathrm{~K}$. Spectra for CDA-Cl and $(\mathrm{CDA})_{3}\left[\mathrm{Fe}(\mathrm{CN})_{6}\right]$ in $\mathrm{CDCl}_{3}$ and $\mathrm{DMSO}-\mathrm{d}_{6}$ are given below (Figures 1, 2, and 3). The numbering scheme for $\mathrm{CDA}^{+}$is as follows:
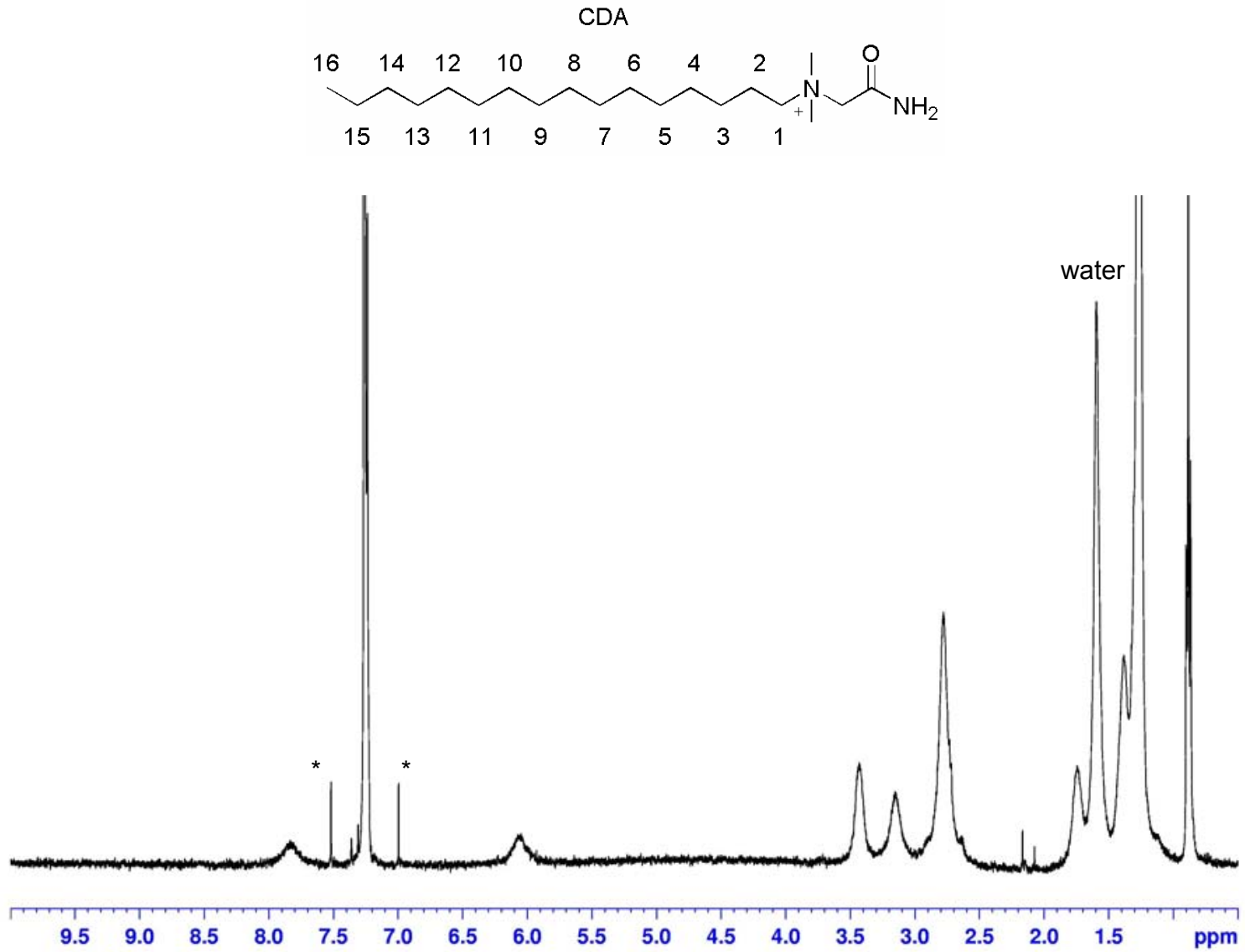

Figure 1. ${ }^{1} \mathrm{H}-\mathrm{NMR}$ spectrum of $(\mathrm{CDA})_{3}\left[\mathrm{Fe}(\mathrm{CN})_{6}\right]$ saturated solution in $\mathrm{CDCl}_{3}$.

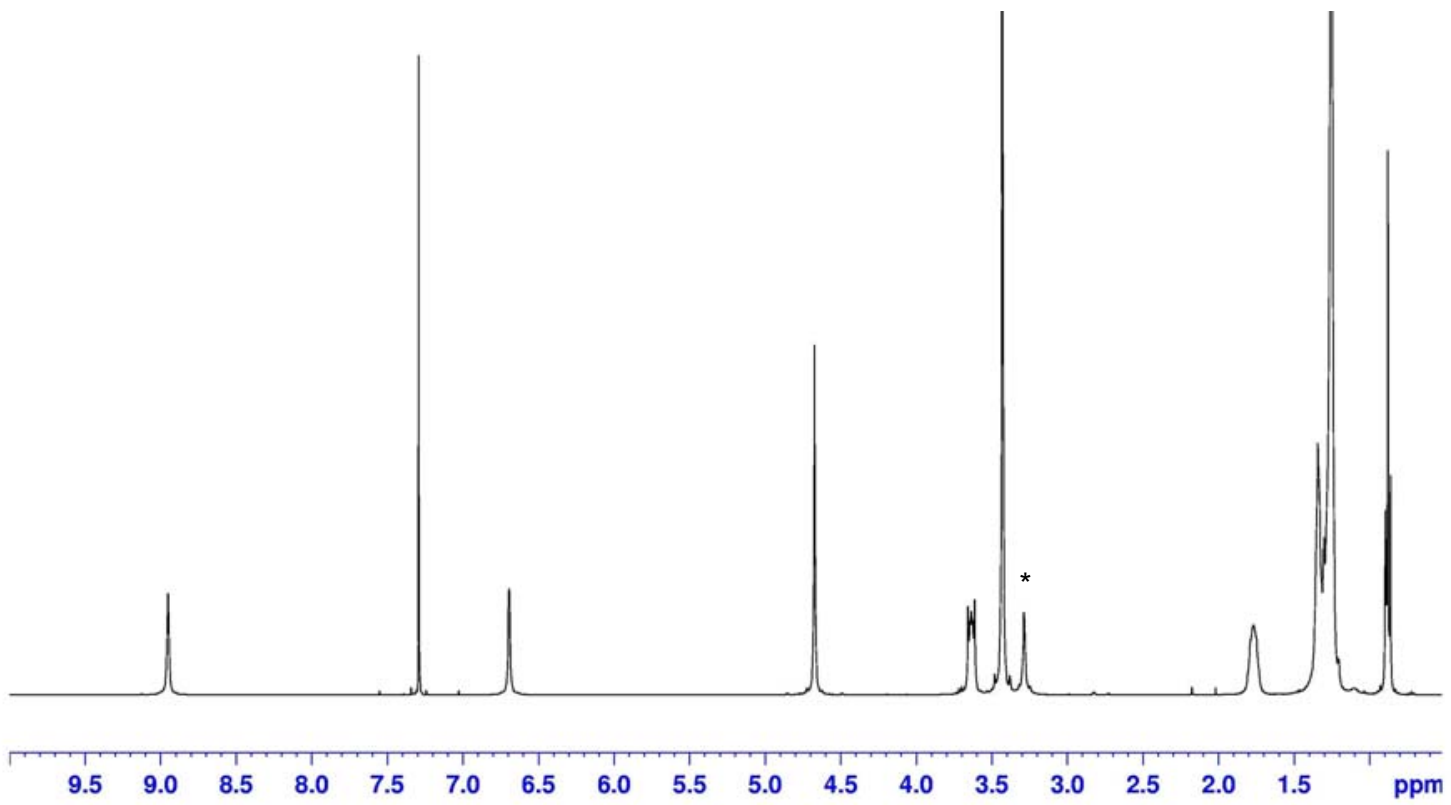

Figure 2. ${ }^{1} \mathrm{H}-\mathrm{NMR}$ spectrum of $\mathrm{CDA}-\mathrm{Cl} 1 \%$ by weight in $\mathrm{CDCl}_{3}$. 


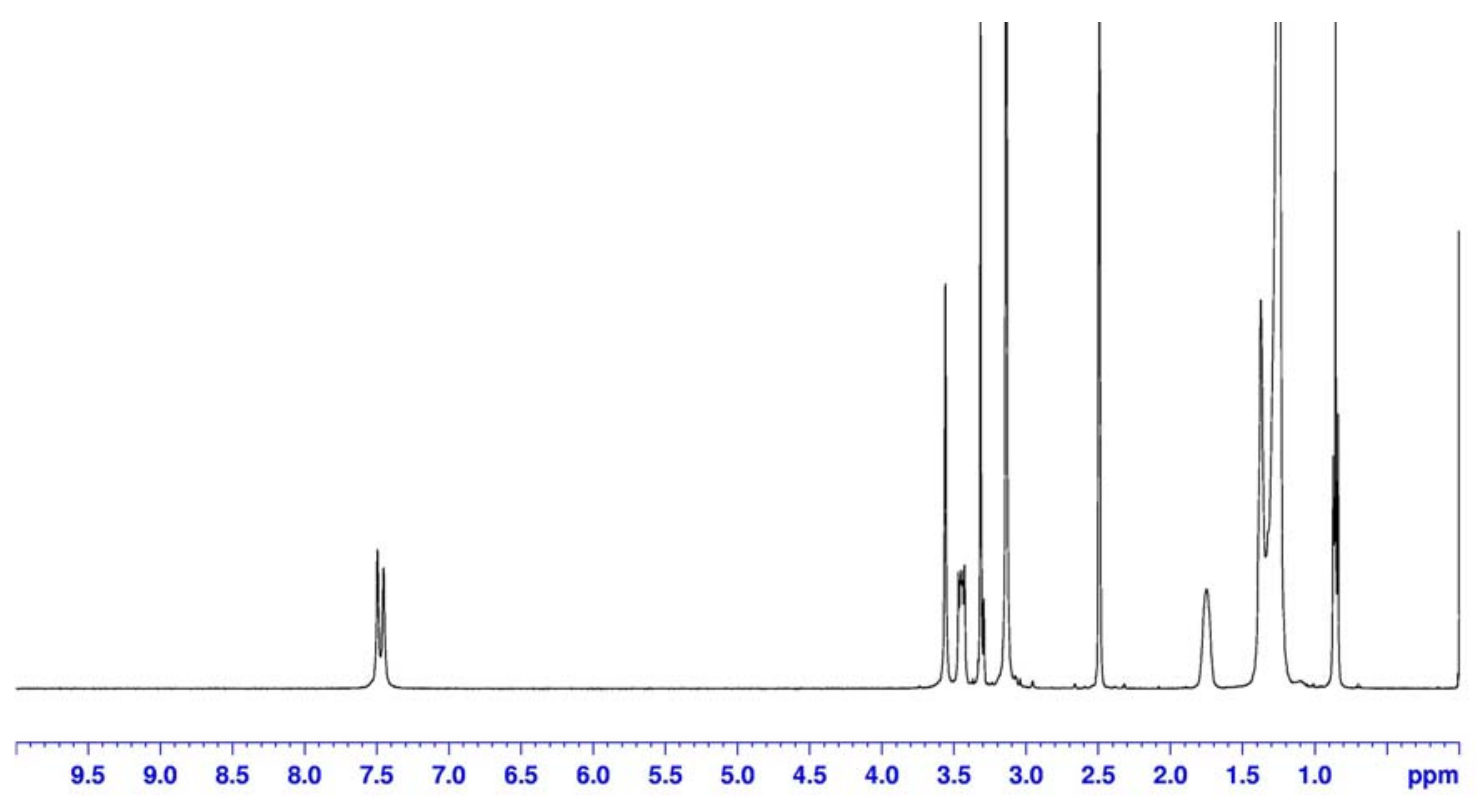

Figure 3. ${ }^{1} \mathrm{H}-\mathrm{NMR}$ spectrum of $(\mathrm{CDA})_{3}\left[\mathrm{Fe}(\mathrm{CN})_{6}\right] 1 \%$ by weight in DMSO.

\section{$X$-Ray Crystallographic Measurements}

Crystal data for $(\mathrm{CDA})_{3}\left[\mathrm{Fe}(\mathrm{CN})_{6}\right] \cdot \mathrm{DMSO}: \mathrm{C}_{68} \mathrm{H}_{135} \mathrm{FeN}_{12} \mathrm{O}_{4} \mathrm{~S}$, fw $=1272.79, T=$ $218(2) \mathrm{K}$, yellow plate, triclinic, $P-1, a=11.6444(15), b=14.3461(17), c=24.658(3)$ $\AA, \alpha=74.053(3), \beta=77.117(2), \gamma=83.995(3)^{\circ}, V=3856.8(8) \AA^{3}, D($ calc $)=1.096$ $\mathrm{Mg} / \mathrm{m}^{3}, Z=2$. All crystals examined diffracted weakly due to the expected high thermal activity of the long alkyl chains. The asymmetric unit consists of three cations, two half anions located on inversion centers, and a molecule of DMSO. All non-hydrogen atoms were refined anisotropically, and hydrogen atoms were placed in idealized locations. $R 1$ $=10.89 \%, w R 2=25.52 \%$. Bruker P4 diffractometer with APEX CCD detector. All software contained in Bruker SMART, SAINT and SHELXTL libraries (Bruker AXS, Madison, WI).

\section{Phase Diagram of $\mathrm{CDA}-\mathrm{Cl} / \mathrm{CHCl}_{3} / \mathrm{H}_{2} \mathrm{O}$ Ternary System}

The $\mathrm{L}_{1}$ and $\mathrm{L}_{2}$ phase boundaries were determined by turbidimetric titrations. Most of the $\mathrm{L}_{2}$ boundary points were obtained by preparing a $\mathrm{CDA}-\mathrm{Cl} / \mathrm{CHCl}$ solution in a $(20 \mathrm{~mL})$ culture tube, and then titrating the addition of water by adding small aliquots (20-200 $\mu \mathrm{L})$ of water. After each aliquot addition, and after carefully recording the respective weights, the tube is shaken and any bubbles are allowed to rise. Brief ultrasonication is often done to promote bubble coalescence. The clarity of the resulting mixture is then judged. If a clear solution has been obtained, the composition is considered to be a single phase microemulsion composition. If the mixture remains turbid, the composition is considered to be in a multiphase domain. When a clear composition is followed by a turbid composition after a subsequent aliquot addition, the midpoint composition between these two is then composed, by adding an appropriate weight of the $\mathrm{CDA}-\mathrm{Cl} / \mathrm{CHCl}_{3}$ solution. If this composition is "clear" an aliquot of water is added at about the midpoint between the closest turbid and clear compositions; if again turbid, an appropriate weight of the $\mathrm{CDA}-\mathrm{Cl} / \mathrm{CHCl}_{3}$ solution is again added. In this way one quickly converges to the boundary point to the degree of uncertainty desired. In these studies, such convergence was taken as sufficient when the deviation for the 
average composition between closest "turbid" and "clear" measurements was less than $1 \%(\mathrm{w} / \mathrm{w})$. In a similar way, solutions of a given $\mathrm{CDA}-\mathrm{Cl} /$ water ratio were titrated with aliquots of $\mathrm{CHCl}_{3}$ to generate most of the $\mathrm{L}_{1}$ domain boundary values. Certain boundary points were simply estimated by preparing compositions with steadily changing component values, and observing where the clear-turbid boundary fell, by averaging the closest clear and turbid compositions. The solubilities of $\mathrm{CDA}-\mathrm{Cl}$ in $\mathrm{CHCl}_{3}$ and in water were estimated this way. The respective solubilities of water and $\mathrm{CHCl}_{3}$ in each other were done by the above described titration procedure. The room temperature at which all of our measurements were made was $22 \pm 1^{\circ} \mathrm{C}$. Some compositions at the highest CDA-Cl levels, within the single phase $\mathrm{L}_{1}$ and $\mathrm{L}_{2}$ domains appeared to have much higher viscosity. These observations suggest transition to very long, rod-like structures, similar to structures reported in other microemulsion systems of cetyltrimethylammonium surfactants. 


\section{Crystal Structure of $(\mathrm{CDA})_{3}\left[\mathrm{Fe}(\mathrm{CN})_{6}\right]$ DMSO: ORTEP Diagram}
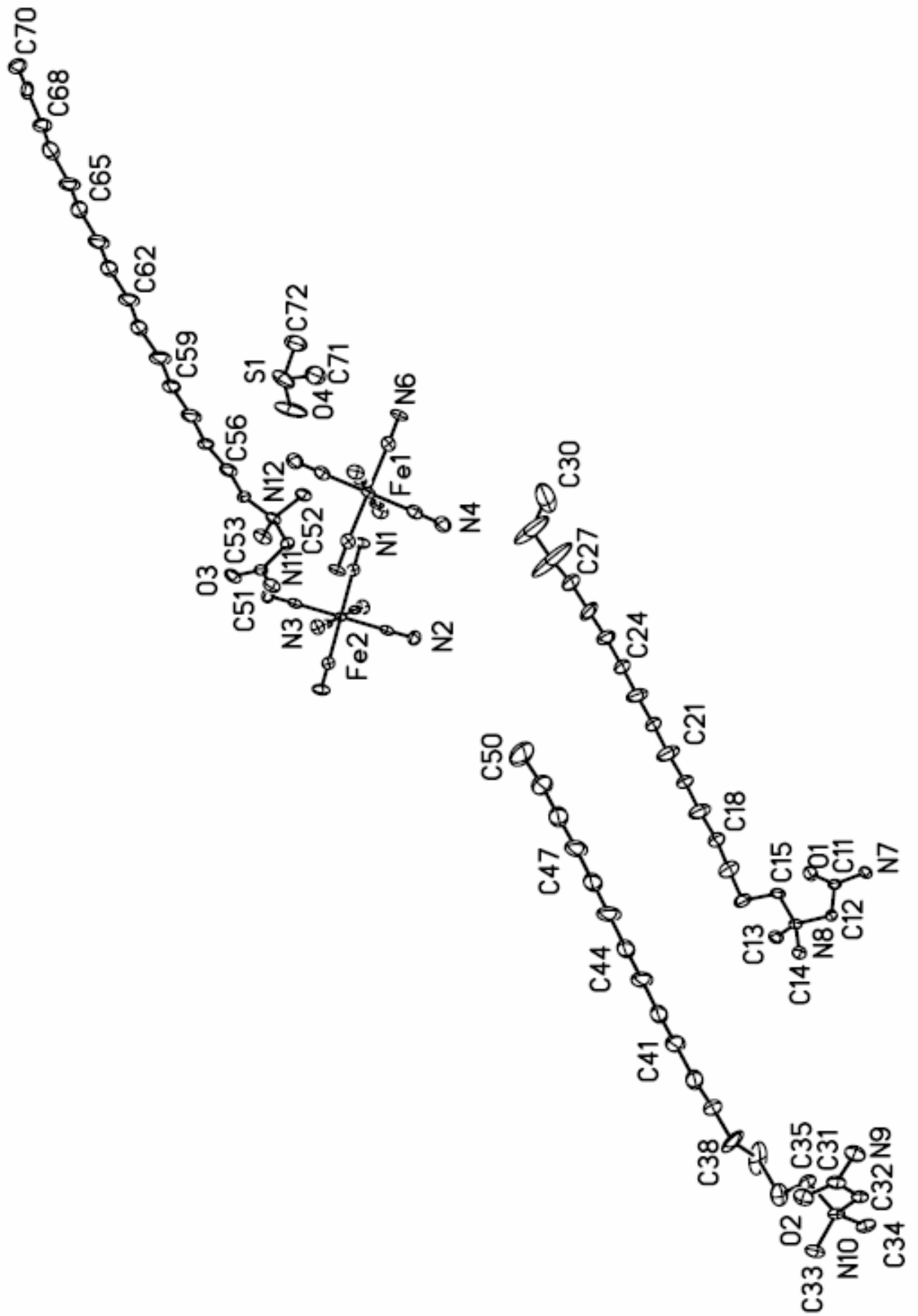


\section{References}

(1) Schiefer, H.; Beger, J.; Lorenz, U., J. Prakt. Chem. 1985, 327(3), 383-98.

(2) Mehltretter, C. L., J. Am. Oil Chem. Soc. 1967, 44(4), 219-20.

(3) Schmidtke, H. H.; Eyring, G., Z. Phys. Chem. 1974, 92(1-6), 211-22.

(4) Ulmius, J.; Lindman, B.; Lindblom, G.; Drakenberg, T., J. Colloid Interf. Sci. 1978, 65(1), 88-97.

(5) Walters, M. A.; Dewan, J. C.; Min, C.; Pinto, S., Inorg. Chem., 1991, 30, 2656-62. 